\title{
The importance of aerobic fitness for tennis: training and testing (part 2)
}

\author{
Cyril Genevois $^{a}$ \\ ${ }^{a}$ Claude Bernard University Lyon 1, Lyon, France.
}

\section{ABSTRACT}

In part 1 of this series we discussed why aerobic fitness is important for tennis players (Genevois, 2019). Scientific studies have revealed that High Intensity Intermittent Training (HIIT) is an efficient way to improve aerobic fitness either off- or on-court, depending on the training phase. The intensity of the training sessions can be individualized based on the final speed reached during the 30/15 Intermittent Fitness Test.

\author{
Key words: High Intensity \\ Intermittent Training, \\ incremental test, periodization. \\ Received: 01 September 2019 \\ Accepted: 10 October 2019 \\ Corresponding author: Cyril \\ Genevois, 6 Grande rue de \\ Saint Clair, Caluire-et-Cuire, \\ Lyon, France 69300. Email: \\ cyril.genevois@aol.fr
}

\section{INTRODUCTION}

Because of the intermittent nature of tennis matches and the alternating demands on energy systems between points and rest, it seems logical that training competitive players should focus on improving their ability to repeatedly perform and recover from high-intensity exercise. For these reasons, tennis training should include physical exercise aimed to enhance both aerobic and anaerobic fitness.

\section{HIGH INTENSITY INTERVAL TRAINING (HIIT) AND ON- COURT TENNIS TRAINING (OTT)}

High intensity-interval training (HIIT) consists of repeated, intense exercise bouts separated by passive or active recovery (work and rest intervals ranging from 10 seconds to 4 minutes; at $90-100 \%$ of the velocity achieved at the level of VO2max; HR values $\geq 90 \%$ of HRmax ; and, work-to-rest ratios of $4: 1$ to $1: 1$ to $1: 4)$. It is as a time-efficient alternative to moderate- or low-intensity continuous exercise for improving variables related to endurance and anaerobic performance both for young players (Engel et al, 2018) and adults (Wen et al, 2019). HIIT replicates the intermittent nature of tennis play at higher intensities and appears a viable exercise programming option because the rest intervals between intense work intervals may contribute to reduced discomfort and inducing a more positive affective response (Thum et al, 2017).

Because training time is at a premium, tennis coaches often rely on an integrated approach and they include technical skills during HIIT session - con-court tennis training(OTT).
The primary purpose of OTT is to combine improvement of physical conditioning with the maintenance of technical skills in order to optimize the training time. Studies comparing playing (OTT) and non-playing (HIIT) aerobic training in tennis found that the physiological demands (average HR) were greater during the playing session compared to the nonplaying session (Fernandez-Fernandez et al, 2011 ; Pialoux et al, 2015 ; Kilit \& Arslan, 2019).

This could be related to the involvement of the lower- and upper-limb muscles in hitting the ball. Indeed, It has been reported that running and striking the ball expends $10 \%$ more energy than running without striking the ball (Bekraoui et al, 2012). Several studies have shown that OTT protocols are effective in improving aerobic fitness in young tennis players with increase in VO2max of $4.8 \%$ (Fernandez-Fernandez et al, 2011), 5.5\% (Kilit \& Arslan, 2019) and 10.28\% (Srihirun et al, 2014). These results are in line with studies using HIIT protocols which showed an increase in VO2max of 6.0\% (Fernandez-Fernandez et al, 2012), 5.2\% (Kilit \& Arslan, 2019), 6.6\% (Srihirun et al, 2014).

The main important factor when planning HIIT or OTT is to achieve the required intensity to elicit improvements. for running-based HIIT activity, the speed is calculated as a percentage of the maximal performance obtained during a fitness test - which can vary depending on the test used. For OTT, it is the combination of running distance between every stroke and ball frequency that determines the intensity. It can be assessed during a specific tennis fitness test (Baiget et al, 2014; Brechbühl et al, 2016) or by monitoring the HR response of the players. 


\section{REPEATED SPRINT TRAINING (RST)}

RST is based on the repetition of " all-out " efforts of short duration ( $\leq 10 \mathrm{~s}$ ) interspersed with short and incomplete recoveries (work:rest ratio of 1:4-1:6). This method differs from the traditional HIIT since exercise intensity is maximal, thereby allowing high recruitment of fast-twitch fibres. The goal of RST is to improve the Repeated sprint ability (RSA). One study in tennis showed significant correlations between performances in RSA tests and VO2max (Tsiprun et al, 2013). The aerobic energy system is an important determinant in recovery rate from intense activity and assists in power output maintenance during the RST.

Although the main goal of RST is to improve the Repeated Sprint Ability (RSA), it has been shown to improve VO2peak level by $4.9 \%$ in tennis (Fernandez-Fernandez et al, 2012). Moreover, the effects of repeated-sprint training in hypoxia (RSH) - low oxygen state - to induce a larger metabolic stimulus have been explored and have shown greater improvement in some tennis-specific physical and technical parameters compared with similar training in normoxia with well-trained tennis players (Brechbühl et al, 2018).

\section{AEROBIC FITNESS TESTING}

Specific Tennis Fitness tests that take into account technical efficiency have been validated scientifically (see part 1 of this series; Genevois, 2019) and could be considered the "Gold Standard". But these tests are exclusively reserved for players in well-structured centres because of the detailed methodology necessary for their successful execution.

For years, national federations have used the multistage fitness test (or $20 \mathrm{~m}$ shuttle run test) to evaluate aerobic fitness due to its practical implementation and ease of use. However, though it involves change of direction (COD), it is still a continuous incremental test and does not represent the intermittent characteristic of tennis. Thus, a better option to assess aerobic fitness, and to better plan run-based HIIT, is the 30-15 Intermittent Fitness Test (30-15IFT). A complete description of the $30-15$ IFT protocol and associated materials (audio file and articles) are available online (click here or view references; 30-15 Intermittent Fitness Test, 2019).

The $30-15$ IFT is an intermittent incremental test with 30 seconds of running at increasing speeds, interspersed with 15second passive recovery periods. Initially, the test was designed in a way where players were required to run back and forth between 2 lines set $40 \mathrm{~m}$ apart at a pace that was governed by a pre-recorded beep (figure 1). A modified version with $28 \mathrm{~m}$ shuttle runs for smaller courts such as basketball, netball and racquet sports is now available as well.

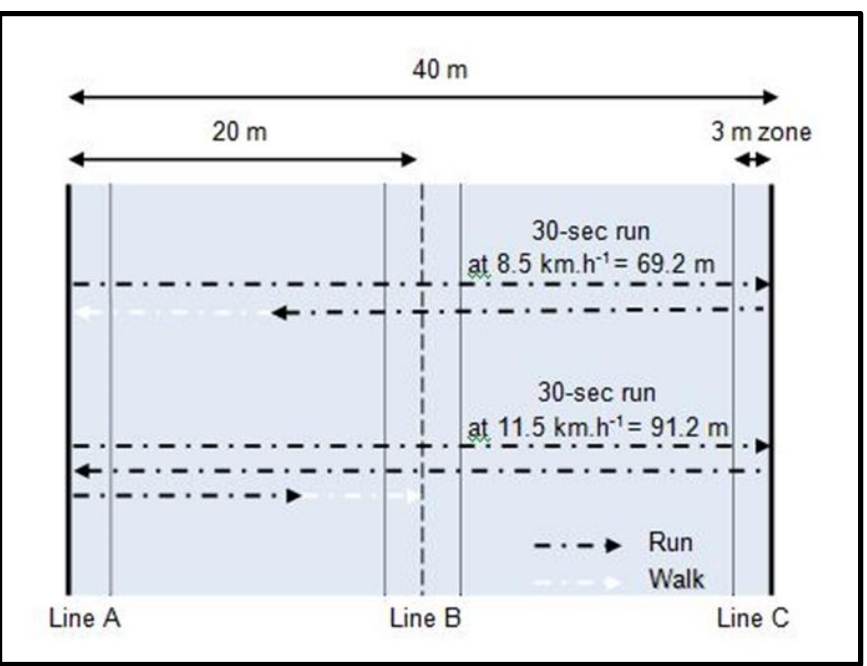

Figure 1. 30/15 IFT protocol with $40 \mathrm{~m}$ shuttle runs.

Because of the intermittent nature of the test, the final speed reached at the end of the test (VIFT) is a compound measure of maximal aerobic power, anaerobic speed reserve, intereffort recovery and change of direction abilities, which are important physical qualities involved in tennis performance.

The 30-15 IFT has been shown to be a valid and reliable measure of V02 max (Buchheit, 2005), when compared to the V02 max achieved during a standard continuous test, while being perceived to be less 'painful' due to the 15 " rest periods.

The velocity $(\mathrm{km} / \mathrm{h})$ attained during the last completed stage (VIFT) is the reference value to individualize speed-based HIIT. But it is important for coaches to understand that the VIFT (i.e. the player's 30-15 IFT score) is not a direct reflection of their maximal aerobic speed obtained with a standard continuous test because of the "anaerobic velocity reserve". Thus, VIFT is on average greater than maximal aerobic speed (VMA) by $15-20 \%$ (2 to $4.5 \mathrm{~km} / \mathrm{h}$ )!!!

\section{IMPLEMENTATION OF HIIT WITH SHORT INTERVALS ON TENNIS COURT USING THE VIFT}

\section{General Preparation phase}

During the general preparation phase ( $\approx 6$ weeks), the goal is to optimize the time at VO2max. Work intervals from 15" to 30 " are used with 2 sessions per week separated by at least $48 \mathrm{~h}$ (table 1). The running distance is calculated from a set running time and the chosen percentage of VIFT.

The work intensity should be slightly lower than that usual for straight line runs to compensate for the loss of time during changes of direction $(\approx 0.7 \mathrm{~s} / \mathrm{COD})$. Indeed, changes of direction induce an increase in the anaerobic metabolism solicitation and consequently creates different responses compared with traditional straight line running (Dellal et al, 2010). Although VIFT is the reference to calculate the running distance, adjustments can be made according to the player 
performance (whether they found it too easy or too hard). Moreover, to compensate for the likely increase in players' fitness throughout the training phase, initial training intensity (\%VIFT) should be increased by 2.5 percent every 2 weeks.

Table 1. Examples of high-intensity intermittent shuttle runs using VIFT as a reference for individualising speed interval duration and distance during the general preparation phases, adapted for tennis players.

\begin{tabular}{|l|l|l|l|l|l|l|l|}
\hline $\begin{array}{l}\text { High- } \\
\text { intensi } \\
\text { ty } \\
\text { durati } \\
\text { on (" } \\
\text { second } \\
\text { s) }\end{array}$ & $\begin{array}{l}\text { Intensi } \\
\text { ty } \\
\text { T) }\end{array}$ & $\begin{array}{l}\text { Recove } \\
\text { ry } \\
\text { duratio } \\
\text { n (" } \\
\text { second } \\
\text { s) }\end{array}$ & $\begin{array}{l}\text { Recove } \\
\text { ry } \\
\text { intensit } \\
\text { y }\end{array}$ & $\begin{array}{l}\text { Runnin } \\
\text { Modali } \\
\text { ty }\end{array}$ & $\begin{array}{l}\text { Max. } \\
\text { series } \\
\text { durati } \\
\text { on ('= } \\
\text { minute } \\
\text { s) }\end{array}$ & $\begin{array}{l}\text { Numb of } \\
\text { series }\end{array}$ & $\begin{array}{l}\text { Recove } \\
\text { ry time } \\
\text { betwee } \\
\text { n series } \\
\text { (' } \\
\text { minute } \\
\text { s) }\end{array}$ \\
\hline $30 "$ & $90 \%$ & $30 "$ & Passive & $\begin{array}{l}\text { Shuttle } \\
30 \mathrm{~m}\end{array}$ & $10^{\prime}-12^{\prime}$ & 2 to 3 & $3^{\prime}$ \\
\hline $20 "$ & $93 \%$ & $20 "$ & Passive & $\begin{array}{l}\text { Shuttle } \\
20 \mathrm{~m}\end{array}$ & $7^{\prime}-8^{\prime}$ & 2 & $3^{\prime}$ \\
\hline $15^{\prime \prime}$ & $95 \%$ & $14 \%$ & Passive & $\begin{array}{l}\text { Shuttle } \\
10 \mathrm{~m}\end{array}$ & $7^{\prime}-8^{\prime}$ & 2 & $3^{\prime}$ \\
\hline
\end{tabular}

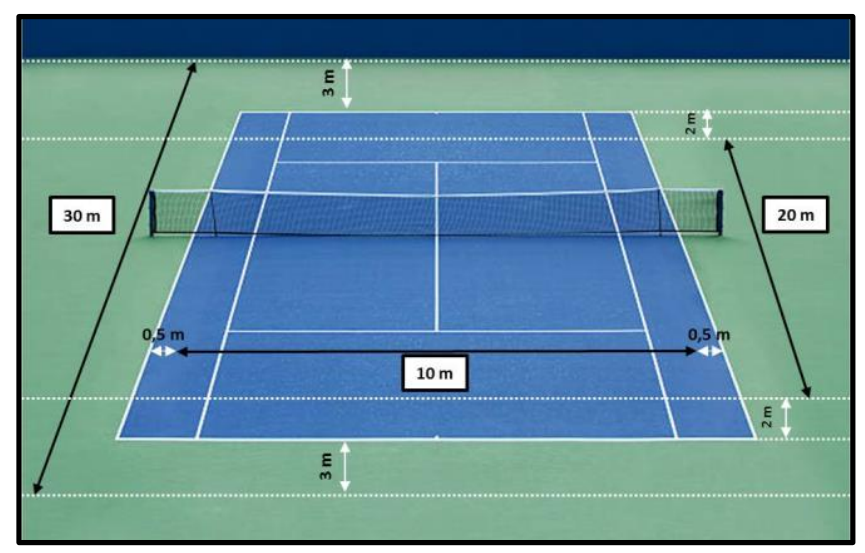

Figure 2. HIIT on tennis court using 10, 20 or 30 m shuttle runs

\section{Specific preparation phase}

During the specific preparation phase ( $\approx 3$ to 6 weeks), the goal is to prepare the players for the specific demands of the match. The primary aim is oriented towards the ability to repeat shorts, high intensity bouts - which are related to the peripheral oxydative capacities - using repeated sprint training (1 session) and on-court specific HIIT (1 session). See table 2 .
Table 2. Repeated Sprint Training (RST) and On-Court specific HIT during the specific preparation phase adapted for tennis players.

\begin{tabular}{|c|c|c|c|c|c|c|c|}
\hline $\begin{array}{l}\text { High- } \\
\text { inten } \\
\text { sity } \\
\text { durat } \\
\text { ion (" } \\
= \\
\text { seco } \\
\text { nds) }\end{array}$ & $\begin{array}{l}\text { Inten } \\
\text { sity }\end{array}$ & $\begin{array}{l}\text { Reco } \\
\text { very } \\
\text { durat } \\
\text { ion (" } \\
= \\
\text { secon } \\
\text { ds) }\end{array}$ & $\begin{array}{l}\text { Reco } \\
\text { very } \\
\text { inten } \\
\text { sity }\end{array}$ & $\begin{array}{l}\text { Runn } \\
\text { ing } \\
\text { Mod } \\
\text { ality }\end{array}$ & $\begin{array}{l}\text { Max. } \\
\text { serie } \\
\text { s } \\
\text { durat } \\
\text { ion } \\
\text { ('= } \\
\text { minu } \\
\text { tes) }\end{array}$ & $\begin{array}{l}\text { Num } \\
\text { ber } \\
\text { of } \\
\text { serie } \\
\text { s }\end{array}$ & $\begin{array}{l}\text { Reco } \\
\text { very } \\
\text { time } \\
\text { betw } \\
\text { een } \\
\text { series } \\
\text { (' = } \\
\text { minut } \\
\text { es) }\end{array}$ \\
\hline 3" & $\begin{array}{l}\text { All- } \\
\text { out }\end{array}$ & $27 "$ & $\begin{array}{l}\text { Passi } \\
\text { ve }\end{array}$ & $\begin{array}{l}\text { Shutt } \\
\text { le 5- } \\
10 \mathrm{~m}\end{array}$ & $6^{\prime}$ & 2 & $\begin{array}{l}6^{\prime}-7^{\prime} \\
\text { activ } \\
\mathrm{e}\end{array}$ \\
\hline $10^{\prime \prime}$ & $\begin{array}{l}\text { RPE > } \\
7\end{array}$ & $20 "$ & $\begin{array}{l}\text { Passi } \\
\text { ve }\end{array}$ & $\begin{array}{l}\text { Hitti } \\
\text { ng } \\
\text { drills }\end{array}$ & $7^{\prime}$ & 2 & $\begin{array}{l}6^{\prime}-7^{\prime} \\
\text { activ } \\
\mathrm{e}\end{array}$ \\
\hline
\end{tabular}

During this phase, RST and On-Court specific HIT are performed at least $48 \mathrm{~h}$ before strength or speed-oriented training sessions, to ensure optimal player freshness in these sessions.

\section{Competition phase}

The competition phase is the most important phase and the goal is to maintain the fitness level that has been previously achieved - while monitoring the training load (high in technical/tactical sessions and specific priority conditioning components such as power). One session per week using oncourt tennis HIIT seems to be the most adapted to this period. However, when the strength/power sessions are not programmed in a particular week, another RST session is preferred to compensate for the lack of neuromuscular load.

\section{CONCLUSION}

High intensity-interval training (HIIT) is a time efficient way to improve aerobic fitness for tennis players. The $30 / 15$ IFT is an intermittent field test allowing coaches to assess the main player's overall fitness performance and to individualise training sessions. 


\section{REFERENCES}

30-15 Intermittent Fitness Test (2019, 1 August). Retrieved from https://30-15ift.com/

Baiget E., Fernandez-Fernandez J., Iglesias X., Vallejo L. \& Rodriguez F.A. (2014). On-court endurance and performance testing in competitive male tennis players. J Strength Cond Res, 28, 256-264, https://doi.org/10.1519/JSC.0b013e3182955dad

Bekraoui N., Fargeas-Gluck M.A. \& Léger L (2012). Oxygen uptake and heart rate response of 6 standardized tennis drills. Appl Physiol Nutr Metab, 37, 982-989, https://doi.org/10.1139/h2012-082

Brechbühl C., Girard O., Millet G.P.\& Schmitt L. (2016). On the Use of a Test to Exhaustion Specific to Tennis (TEST) with Ball Hitting by Elite Players. PLoS ONE 11(4): e0152389, https://doi.org/10.1371/journal.pone.0152389

Brechbuhl C., Brocherie F., Millet G.P., \& Schmitt L. (2018). Effects of Repeated-Sprint Training in Hypoxia on TennisSpecific Performance in Well-Trained Players. Sports medicine international open, 2(5), E123-E132. Doi:10.1055/a-0719-4797, https://doi.org/10.1055/a0719-4797

Buchheit, M. (2005). The 30-15 intermittent fitness test: reliability and implication for interval training of intermittent sport players. In: ECSS Proceedings. Belgrade.

Dellal A., Keller D., Carling C., Chaouachi A., Wong del P. \& Chamari K. (2010). Physiologic effects of directional changes in intermittent exercise in soccer players. J Strength Cond Res, 24(12), 3219-26, https://doi.org/10.1519/JSC.0b013e3181b94a63

Engel F.A., Ackermann A., Chtourou H., \& Sperlich B. (2018). High-Intensity Interval Training Performed by Young Athletes: A Systematic Review and Meta-Analysis. Frontiers in physiology, 9, 1012. doi:10.3389/fphys.2018.01012, https://doi.org/10.3389/fphys.2018.01012

Fernandez-Fernandez J., Sanz-Rivas D., Sanchez-Munoz C., Gonzalez de la Aleja Tellez J., Buchheit M. \& MendezVillanueva A. (2011). Physiological responses to on-court vs running interval training in competitive tennis players. J Sports Sci Med, 10, 540-545.

Fernandez-Fernandez J., Zimek R., Wiewelhove T., and Ferrauti A. (2012). High intensity interval training vs. Repeated sprint training in tennis. J Strength Cond Res, 26(1),

53-62, https://doi.org/10.1519/JSC.0b013e318220b4ff

Kilit B. and Arslan E. (2019). Effects of high-intensity interval training vs. on-court tennis training in young tennis players. J Strength Cond Res, 33(1), 188-196, https://doi.org/10.1519/JSC.0000000000002766

Pialoux V., Genevois C., Capoen A., Forbes S.C., Thomas J. \& Rogowski I. (2015) Playing vs. Nonplaying Aerobic Training in Tennis: Physiological and Performance Outcomes. PLoS ONE 10(3): e0122718. doi:10.1371/journal.pone.0122718, https://doi.org/10.1371/journal.pone.0122718

Srihirun K., Boonrod W., Mickleborough T.D. \& Suksom D. (2014). The Effect of On-Court vs. Off-Court Interval Training on Skill Tennis Performance and Fatigue in Tennis Training. JEPonline, 17(5), 11-20, https://doi.org/10.1249/01.mss.0000493952.58661.7e

Thum J.S., Parsons G., Whittle T. \& Astorino T.A. (2017). Highintensity interval training elicits higher enjoyment than moderate intensity continuous exercise. PLoS One, 12(1):e0166299,

https://doi.org/10.1371/journal.pone.0166299

Tsiprun I., Eisenstein T., Eliakim A., Nemet D. \& Meckel Y.

(2013). Relationships among repeated sprint tests and aerobic fitness in adolescent tennis players. Acta Kinesiologiae Universitatis Tartuensis, 19, 31-40, https://doi.org/10.12697/akut.2013.19.03

Wen D., Utesch T., Wu J., Robertson S., Liu J., Hu G. \& Chen H. (2019). Effects of different protocols of high intensity interval training for $\mathrm{VO} 2 \mathrm{max}$ improvements in adults: A meta-analysis of randomised controlled trials. J Sci Med Sport, 22(8), 941-947, https://doi.org/10.1016/j.jsams.2019.01.013

RECOMMENDED ITF TENNIS ACADEMY CONTENT (CLICK BELOW)

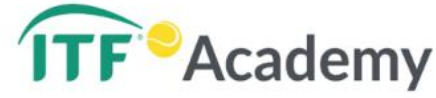

Copyright (c) 2019 Cyril Genevois

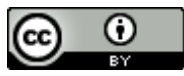

This text is under a Creative Commons BY 4.0 license

You are free to Share - copy and redistribute the material in any medium or format - and Adapt the content - remix, transform, and build upon the material for any purpose, even commercially under the following terms:

Attribution: You must give appropriate credit, provide a link to the license, and indicate if changes were made. You may do so in any reasonable manner, but not in any way that suggests the licensor endorses you or your use.

CCBY 4.0 license terms summary CCBY4.0 license terms 